http://jmscr.igmpublication.org/home/ ISSN (e)-2347-176x ISSN (p) 2455-0450 crossref DOI: https://dx.doi.org/10.18535/jmscr/v8i6.14

\title{
Incidence and Obstetric Outcome of Teenage Pregnancies at a Tertiary Hospital in Southern Nigeria
}

\section{Authors \\ Mbereobong Etuk ${ }^{1 *}, J_{0 a n f r e d a ~ E t u k}^{2}$, Inimfon Jackson $^{3}$, Success Effanga $^{1}$, Saturday Etuk ${ }^{1,4}$}

${ }^{1}$ Department of Obstetrics and Gynaecology, University of Uyo Teaching Hospital, Uyo. Akwa Ibom State, Nigeria

${ }^{2}$ Department of Pediatrics, University of Uyo Teaching Hospital, Uyo, Akwa Ibom State, Nigeria

${ }^{3}$ Department of Epidemiology, University of Texas Health Science Center at Houston Houston, Texas 77030

United States of America

${ }^{4}$ Department of Obstetrics and Gynaecology, University of Calabar Teaching Hospital, Calabar, Cross River

State, Nigeria

*Corresponding Author

Mbereobong Saturday Etuk

Department of Obstetrics and Gynaecology, University of Uyo Teaching Hospital, Uyo. Akwa Ibom State Nigeria

\begin{abstract}
Pregnancy in a teenager is a high risk and complex condition with associated maternal and fetal complications. This is because the teenage mother is still undergoing physical, psychological, emotional, and social development.

The aim of this study was to assess the sociodemographic characteristics of teenage pregnant mothers in southern Nigeria and to analyse the difference in outcomes between booked and un-booked women.

This was a 5-year retrospective observational study of 6,964 deliveries conducted at a tertiary hospital in southern Nigeria.

The incidence of teenage pregnancy during the period under review was $1.95 \%$. The majority (68.4\%) of the teenage mothers had completed secondary education. Pregnancy complications that were common amongst them included; anaemia (41.9\%), pre-eclampsialeclampsia (14\%), preterm delivery(19.4\%), low birth weight $(21.5 \%)$ and still birth (3.2\%). The caesarean section and instrumental delivery rates were $0.5 \%$ and $5.1 \%$ respectively. There was a complication rate of $(64.5 \%)$ amongst the un-booked teenage mothers. Furthermore, majority of teenage pregnant mothers who developed anaemia (82\%), preeclampsia (77\%) and still birth deliveries (100\%) were unbooked teenage mothers.

Teenage pregnancy is a public health problem with diverse consequences, which are more pronounced in those who lack the opportunity to receive skilled care. Creation of awareness, proper contraceptive use, girl child education and quality obstetric care would reduce the prevalence of teenage pregnancy and possible complications.

Keywords: Incidence, pregnancy, teenage pregnancy, adolescent pregnancy, obstetric outcome.
\end{abstract}




\section{Introduction}

Teenage pregnancy is a social hazard with serious medical consequences. It is a high risk condition demanding skilled care in order to achieve favorable pregnancy outcomes. Teenage pregnancy is defined as pregnancy in a girl aged between 10-19 years ${ }^{1}$. It is also referred to as adolescent pregnancy ${ }^{1}$. The teenage years are a unique and distinct physical and developmental stage in the life of a woman. This period corresponds to a time when a young girl gradually transits from childhood to adulthood with a potential conflict between biological and social factors $^{1,2}$. There is also a concurrent physical, psychological, emotional, and social development on-going at this time ${ }^{1-5}$. It is a problem of a child habouring a child and shouldering the attendant responsibilities $^{3}$. Pregnancy in them is often unplanned, unwanted, and usually results from unstable intimate relationships ${ }^{3}$.

Pregnancy in an adolescent is generally considered to be a high risk condition with varying incidence across the globe ${ }^{2}$. Adolescents constitute nearly $20 \%$ of the world's population; $85 \%$ of these adolescents live in developing countries and out of these, about $16 \%$ live in Africa $^{5}$. The number of pregnancies among teenagers is increasing throughout the world. Globally, 15 million girls aged 15-19 have babies yearly $^{6}$. Hence, pregnancy in the adolescent, accounts for approximately $10 \%$ of all births worldwide $^{6,7}$. In Nigeria, the incidence of teenage pregnancy is $25 \%$ and the median age at first sexual intercourse was 15.6years among women with no education and 21.2 years among women with more than secondary education. Studies have recorded that $50 \%$ of adolescent pregnancies occur within the first 6 months of initiating sexual intercourse ${ }^{2}$.

The emergence of this socially inflicted health problem has been associated with numerous factors such as early marriage, early age at sexual debut, ignorance and lack of availability or failure to use contraceptives ${ }^{9-10}$. Pre-existing psychosocial problems in the family, maternal deprivation, growing up in a single parent household, having a mother who was an adolescent mother, or having a sister who was a teenage mother are the other critical life events associated with becoming a teenage mother ${ }^{1}$. Other factors include poverty, low self-esteem of girls and low level of education, sexual assault, early pubertal development, the lack of caring parents, lack of school or career goals, and poor school performance or dropping out of school among others ${ }^{2}$. Most of these pregnancies resulted from coitus with partners of similar age who are not more advantaged socially.

Pregnancy in the adolescent girl is fraught with myriads of complications such as anaemia from malaria and inadequate nutrition, preterm labour and delivery, pre-eclampsia and eclampsia, antepartum haemorrhage and feto pelvic disproportion with its attendant risks of high operative intervention rates, obstructed labour and its sequelae, notably genital fistulae ${ }^{1,3,7,10-13}$. Other complications include hyperemesis gravidarum, spontaneous or induced miscarriages ${ }^{1}$. Teenage mothers have a higher incidence of low birth weight babies ${ }^{2,5,9-15}$. The typical outcome in most cases is for both the mother and child to be exposed to untold hardship, poverty, starvation, deprivation and poor health. A vicious cycle then ensues and the problem continues from one generation to another.

The decision to conduct the study was conceived due to paucity of recent data or studies on teenage pregnancy in our centre. It intends to highlight the sociodemographic parameters of teenage pregnant mothers, analyse the differences in outcomes between booked and unbooked women.

\section{Materials and Methods}

This study was conducted in Uyo, Akwa Ibom state. It is an oil producing state in southern Nigeria, with a population of $5,450,758$. This study was carried out in the only tertiary health facility in the state.

This was a retrospective observational study of 6,964 deliveries at University of Uyo Teaching 
Hospital over a 5 year period which started from

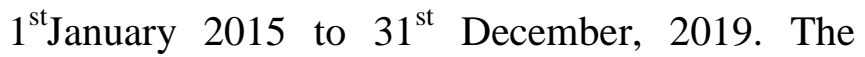
records from the labour ward, the obstetrics theatre, and the special and sick babies unit were reviewed for deliveries by teenage mothers. The records of all deliveries that took place during the period were reviewed and the hospital numbers of all the teenage pregnant mothers were collected. The delivery records of teenage mothers as well as their case files were obtained and relevant variables extracted. Complementary information was also retrieved from the babies' case notes from the neonatal unit.

These records were analysed and the variables extracted included maternal age, gestational age, marital status, educational status, booking status, mode of delivery and maternal and perinatal outcome. The data obtained were analyzed using Microsoft Excel 2007 and results presented in frequency tables and percentages.

\section{Results}

During the period under review a total of 6,964 deliveries were conducted in the facility out of which 136 of them were from teenage mothers, giving a teenage pregnancy rate of 19.5 per 1000 deliveries in the centre.

Table 1: Socio demographic characteristics of teenage mothers

\begin{tabular}{|l|c|c|}
\hline Variables & Frequency & Percentage (\%) \\
\hline Age (years) & & \\
\hline 14 & 5 & 3.7 \\
\hline 15 & 17 & 12.5 \\
\hline 16 & 9 & 6.6 \\
\hline 17 & 5 & 3.7 \\
\hline 18 & 66 & 48.5 \\
\hline 19 & 34 & 25 \\
\hline Total & 136 & 100 \\
\hline Marital status & & \\
\hline Single & 97 & 71.3 \\
\hline Married & 39 & 28.7 \\
Total & 136 & 100 \\
\hline & & \\
\hline Booking status & & \\
\hline Booked & 70 & 51.5 \\
\hline Un booked & 66 & 48.5 \\
Total & 136 & 100 \\
\hline & & \\
\hline Educational status & & 31.6 \\
\hline Primary & 43 & 68.4 \\
\hline Secondary & 93 & 100 \\
Total & 136 & \\
\hline
\end{tabular}

Table 1 shows the sociodemographic characteristics of the teenage pregnant mothers over the study period. The ages of the teenage pregnant mothers ranged from 14 to 19 years with a mean age of 17.5years. Sixty-six out of 136 $(48.5 \%)$ teenage mothers were 18years of age and were mostly 97 (71.3\%) single. Seventy (51.5\%) of the subjects were booked and ninety three $(68.4 \%)$ of them had their secondary education.

Table 2: Mode of delivery, frequency and complication among teenage mothers

\begin{tabular}{|l|c|c|}
\hline Mode of delivery & Frequency & Percentage (\%) \\
\hline Spontaneous vertex & 97 & 71.3 \\
\hline Caesarean section & 28 & 20.5 \\
\hline Vacuum delivery & 7 & 5.1 \\
\hline $\begin{array}{l}\text { Assisted breech } \\
\text { delivery }\end{array}$ & 4 & 2.9 \\
\hline & & \\
\hline Complications & & \\
\hline Anaemia & 39 & 41.9 \\
\hline Pre eclampsia & 13 & 14.0 \\
\hline Preterm labour & 18 & 19.4 \\
\hline Low birth weight & 20 & 21.5 \\
\hline Still birth & 3 & 3.2 \\
Total & 93 & 100 \\
\hline
\end{tabular}

Table 2 illustrates the mode of delivery and the pregnancy complications amongst the teenage mothers. Ninety seven $(71.3 \%)$ of the teenage mothers had spontaneous vertex delivery, while twenty eight (20.5\%) of them delivered by caesarean section. Assisted breech delivery was conducted for four $(2.9 \%)$ of them who were unbooked and presented late in labour. Seven $(5.1 \%)$ of the teenage mothers had vacuum delivery. Thirty nine $(41.9 \%)$ of the subjects were noticed to be anaemic postpartum.

Table 3: Indications for caesarean section in Teenage Pregnant Women

\begin{tabular}{|l|c|c|}
\hline Indication & Frequency & Percentage (\%) \\
\hline Pre eclampsia & 15 & 53.6 \\
\hline $\begin{array}{l}\text { Cephaopelvic } \\
\text { disproportion }\end{array}$ & 07 & 25 \\
\hline Fetal distress & 3 & 10.7 \\
\hline Placenta previa & 2 & 7.1 \\
\hline Cord prolapsed & 1 & 3.6 \\
\hline Total & 28 & $100 \%$ \\
\hline
\end{tabular}


Table 3 displays the indications for caesarean delivery amongst the teenage mothers. Preeclampsia/eclampsia with unfavourable cervix formed the basis for most of the caesarean deliveries fifteen $(53.6 \%)$, closely followed by fetal distress three $(10.7 \%)$.

Table 4: Fetal outcome in Teenage mothers

\begin{tabular}{|l|c|c|}
\hline $\begin{array}{l}\text { APGAR Scores } \\
(5 \mathrm{mins})\end{array}$ & Frequency & $\begin{array}{c}\text { Percentage } \\
(\%)\end{array}$ \\
\hline$<3$ & 11 & 8.1 \\
$4-6$ & 24 & 17.6 \\
\hline$>7$ & 101 & 74.3 \\
\hline & & \\
\hline Birth weight & & \\
\hline$<2.5 \mathrm{~kg}$ & 20 & 14.7 \\
\hline $2.5-3.99 \mathrm{~kg}$ & 108 & 79.4 \\
\hline$>4.0 \mathrm{~kg}$ & 8 & 5.9 \\
\hline
\end{tabular}

Table 4 shows the fetal outcome following delivery by teenage mothers. One hundred and one $(74.3 \%)$ of the teenage mothers delivered babies with APGAR scores greater than 7 , while twenty (14.7\%) of the babies delivered had a birth weight less than 2.5kilogrammes.

Table 5: Obstetric outcomes in relation to booking status in Teenage mothers

$\begin{array}{lcll}\text { Variables } & \text { Booked } & \text { Un-booked } & \text { Total } \\ \text { Anaemia } & 7(18 \%) & 32(82 \%) & 39(100 \%) \\ \text { Pre eclampsia } & 3(23 \%) & 10(77 \%) & 13(100 \%) \\ \text { Preterm Labour } & 12(67 \%) & 6(33 \%) & 18(100 \%) \\ \text { Low Birth Weight } & 11(55 \%) & 9(45 \%) & 20(100 \%) \\ \text { Still Birth } & 0 & 3(100 \%) & 3(100 \%) \\ \text { TOTAL } & 33(35.5 \%) & 60(64.5 \%) & 93(100 \%)\end{array}$

Table 5 shows the obstetric outcome in relation to the booking status of the teenage mothers. Ten $(77 \%)$ of the teenage mothers who did not receive antenatal care, developed pre-eclampsia while seven $(18 \%)$ of those who received antenatal care developed anaemia. Three $(100 \%)$ of the unbooked teenage mothers had still births while twelve $(67 \%)$ of them who booked for antenatal care experienced preterm labour. Majority of teenage pregnant mothers who developed anaemia (82\%), pre-eclampsia (77\%) and still birth deliveries $(100 \%)$ were unbooked teenage mothers.

\section{Discussion}

The incidence of teenage pregnancy from this study was $1.95 \%$, close to $1.67 \%^{10}$ from a similar study in Enugu but much lower than $5.8 \%{ }^{11}$, $6.5 \%^{2}, 9.8 \%$ and $28.6 \%$ in Kano, Calabar, Uyo and Ethiopia respectively. The low incidence, $1.95 \%$ may be as a result of the free and compulsory education policy of the previous and current government in Akwalbom state for primary and secondary levels of education. This low prevalence may also result from patronage of unorthodox health facilities especially by the supported teenage mothers.

The study showed that most of the pregnant teens were 18years (48.5\%) of age which is around the time most of them completed their secondary school education. A significant proportion of them $71.3 \%$ were unmarried and in unstable intimate relationships hence bringing to fore, the early age at sexual debut and the ignorance of or lack of availability of contraceptive options. This is largely different from findings in Northern Nigeria where most teenage mothers are married and are well supported $^{16,17}$.

About $48.5 \%$ of the teenage pregnant girls did not book for antenatal care. Those of them who booked, registered late and a large number did not have the support of the families. These may explain the high complication rate recorded in these young mothers, which is not far different from most other studies ${ }^{12,14 \text {, and } 15}$.

The caesarean section rate among the teenage mothers was $20.5 \%$, similar to that reported by Ezegwui (18.9\%) and Ibrahim (18.9\%) in Enugu and Kano respectively and also similar to a study by Emem (22.5\%) in Uyo. Pre-eclapmsia/ eclampsia with unfavourable cervix $(53.6 \%)$ and cephalopelvic disproportion (25\%) accounted for most caesarean sections performed similar to findings from most studies in Northern Nigeria. This is not unexpected as most of them are carrying their first pregnancies which is a predisposing factor to pre-eclampsia/eclampsia and their pelvises are not fully developed. The instrumental delivery rate was $5.1 \%$ mostly due to 
delayed second stage of labour following poor maternal effort.

The complications noticed among teenage pregnant mothers were not different from those noticed in most other studies. Anaemia (41.9\%) was the commonest complication reported and similar to the earlier study done in the same hospital $^{4}$. This could have been due to poor nutrition, malaria and haemolysis following preeclampsia. Anaemia together with Pre-eclampsia could have accounted for the low birth weight and preterm delivery rate of $21.5 \%$ and $19.4 \%$ respectively.

The incidence of low Apgar scores (less than 7) among babies of teenage mothers was $25.7 \%$. This may not be unconnected with the fact that a number of them were unbooked. The complication rate amongst booked and un-booked teenage mothers was $35.5 \%$ and $64.5 \%$ respectively, highlighting the need for antenatal care amongst teenage mothers.

This study has highlighted the poor maternal and perinatal outcomes associated with pregnancy in un-booked teenage mothers, while showcasing the place of girl child education. Creation of awareness and proper contraceptive use would also reduce the rate of unwanted pregnancy among teenagers. Antenatal care should be made more assessable and affordable to teenage mothers in other to improve obstetric outcome.

\section{Acknowledgements}

We most sincerely appreciate the contribution of the staff of the Department of Health records and statistics of the University of Uyo Teaching Hospital; Uyo to the success of this review.

\section{References}

1. Cornelius MD, GoldscmidtL, Willford JA. Offsprings of teenage mothers. Maternal and childhealth Journal.2008; 13(6): 847856.

2. Iklaki CU, Inaku JU, Ekabua JE, Ekanem EI, Udo AE. Perinatal Outcome in Unbooked Teenage Pregnancies in the
University of Calabar Teaching Hospital, Calabar, Nigeria. ISRN Obstet Gynecol, 2012: $1-5$.

3. Jimoh AS, Abdul IF. Outcome of teenage pregnancies in Ilorin, Nigeria. Trop $\mathrm{J}$ Obstet Gynaecol, 2004; 21 (1): 27 - 31

4. Emem BA, Abasiattai AM, Abasiubong F. Outcome of Teenage Pregnant mothers in Uyo, Nigeria. Tropical Journal of Medical Research;2006;101

5. Banerjee B, Pandey G, Dutt D. Teenage pregnancy: A socially inflicted health hazard. IJCM. 2009. 34(3): 227-231.

6. World Health Organisation Regional Office for Africa. Adolescent health: A strategy for the African region. AFR/RC51/10 Rev. 1 Brazzaville, 2001.

7. Fleming N, Ottawa ON, O’Driscoll $\mathrm{T}$ et al. Adolescent pregnancy guidelines. $\mathrm{J}$ ObstetGynaecol 2015;37(8):740-756.

8. Olukoya AA, Ferguson J. Adolescent sexual and Reprodudtive Health and Development. Archives of Ibadan Medicine. 2002; 3 (1): 22 - 27.

9. Adeyinka DA,Oladimeji O, Adekanbi OT, Adeyinka FE, Falope $\mathrm{Y}$,Aimakhu C. Outcome of adolescent pregnancies in southwestern Nigeria: a case-control study. J Matern Foetal Neonatal Med, 2010; 23(8): 785-789

10. Ndifon WO, Ogaji DST, Etuk SJ. Sexuality, contraception and unintended pregnancy amongst female student nurses in calabar, Nigeria.

11. Ezegwui HU, Ikeako LC, Ogbuefi F. Obstetric Outcome of teenage pregnancies at a tertiary hospital in Enugu, Nigeria. Nigerian journal of clinical practice. Aprjun 2012.vol 15. Issue 2, 147-150.

12. Garba I, Adewale TM, Ayyuba R, Abubakar IS. Obstetric outcome of teenage pregnancy at Aminu Kano Teaching Hospital: A 3year review. Journal of Medicine in the Tropics 15 oct 2013 
13. Onoh RC, Ezeonu PO, Anozie BO, Esike COU, Obuna JA, Egbuji C, et al. Outcome of Teenage pregnancy at a Tertiary Hospital in Abakaliki Southeast Nigeria. Journal of Basic and Clinical Reproductive Science. Vol 3, No 1 (2014)

14. Udo A, Ekott M, Ekanem E. Teenage Pregnancy and Adverse Birth Outcomes in Calabar, Nigeria. The internet Journal of Gyneacology and Obstetrics Volume 17 Number 2

15. Habitu YA, Yalew A, Bisetegn TA. Prevalence and factors associated with teenage pregnancy, Northeast Ethiopia, 2017: A cross sectional study. Journal of pregnancy. Volume 2018, Article ID1714527,7 pages https://doi.org/10.1155/2018/1714527.

16. Nwobodo EI, Adoke EU. Obstetric outcome of Teenage pregnancies at a Tertiary care hospital in Sokoto, Nigeria. Tropical journal of Obstetrics and Gynaecology, vol 22(2)2005: 168-170.

17. Maduforo AN. Prevalence of Adolescent Pregnancy in Ganye Local Government Area Adamawa state, Nigeria. JORIND 9(2) December 2011. ISSN 15968308.www.transcampus.org,www.ajol.info /journals/jorind. 